\title{
Impact of duplicate CT scan rate after implementation of transfer image repository system at a level 1 trauma center
}

\author{
Charles W. Sheppard ${ }^{1} \cdot$ Amy L. Groll ${ }^{2} \cdot$ Cindy L. Austin $^{3} \cdot$ Simon J. Thompson ${ }^{3}$ \\ Received: 13 October 2017 / Accepted: 27 December 2017 / Published online: 12 January 2018 \\ (C) The Author(s) 2018. This article is an open access publication
}

\begin{abstract}
Purpose The regionalization of trauma in the USA results in frequent transfers of patients from a primary hospital ED to a higher level trauma facility. While many hospitals have a Picture Archive Communication System (PACS) which captures digital radiological images, these are often not available to the receiving institution resulting in duplicate imaging. The state of Arkansas instituted a trauma image repository (TIR) in July 2013. We examined whether implementation of this repository would impact CT scan duplication in the trauma system.

Methods This was a retrospective analysis of trauma patients transferred from outlying hospitals in Arkansas and Missouri to a single level 1 trauma hospital in Missouri between July 2012 and June 2015. We compared the duplicate CT rate for patients transferred from Arkansas and Missouri hospitals before and after the repository was implemented for Arkansas.

Results Prior to implementation (July 2012-June 2013) of Arkansas TIR, duplicate CT rates were similar for patients transferred from Arkansas (11.5\% \pm 2.8 ) or Missouri (16.3\% \pm 7.5 ). Following implementation (July 2013-June 2014), the duplicate CT rate for patients transferred from Arkansas was significantly lower (Arkansas $=10.1 \%$ vs. Missouri $16.2 \%$; CI 95\%, $p=0.02$ ), and significance continued (Arkansas $=9.0 \%$ vs. Missouri $=17.8 \%$; CI 95\%, $p=0.02$ ) during follow-up (July 2014-June 2015).

Conclusion Fewer patients received duplicated scans within the Arkansas as compared with the Missouri-based trauma referral systems regardless of Injury Severity Scores (ISS). Our findings suggest that TIR adoption coupled with PACS improved transferability of radiographic studies and could improve patient care while reducing costs in trauma transfers.
\end{abstract}

Keywords CT/MRI · Trauma · Imaging · Critical care transport · Transfer image repository $\cdot$ Duplicate CT $\cdot$ Computed tomography

\section{Introduction}

The regionalization of trauma in the USA [1], Canada [2], Europe [3], and other parts of the world [4, 5] results in frequent transfers of patients from a primary hospital emergency department to a higher level trauma facility [6]. Currently, most hospitals in the USA have a Picture Archive Communication System

Cindy L. Austin

Cindy.austin@mercy.net

1 Department of Emergency Medicine, Mercy Hospital Springfield, 1235 E Cherokee St, Springfield, MO 65804, USA

2 Emergency Department, Mercy Hospital Springfield, 1235 E Cherokee St, Springfield, MO 65804, USA

3 Trauma and Burn Research, Mercy Hospital Springfield, 1235 E Cherokee St, 7H, Springfield, MO 65804, USA
(PACS) which captures digital radiological images providing convenient access to images from within one hospital, or a localized group of affiliated hospitals [7]. Initially, the benefit (reviewed by Becker and Arenson 1994 [8]) touted by the introduction of PACS was a reduction in radiation exposure and cost, due to the reduced need to retake the same images [9]. Although the implementation of PACS proved helpful within intra-hospital transfers, problems remained for inter-hospital transfers since images were often not available to the receiving institution, once again resulting in duplicate patient imaging [10].

A review of the literature indicates a vast range of duplicate computed tomography (CT) averages when trauma patients are transferred into a higher level trauma hospital (28-91\%; [3, 4, 11-14]). According to Chwals et al. (2008), approximately $50 \%$ of trauma patients receive at least one CT at the primary hospital before being transported to the tertiary hospital [14]. Not only does the lack of readily available images impact the timeliness of critical patient care but also the 
necessary time for the actual CT scanning procedure. Research has shown the average length of time for a CT procedure is approximately $22 \mathrm{~min}$ [15]; however, a more recent report found that trauma patients undergoing CT procedures actually had an average increased length of stay (LOS) of $90 \mathrm{~min}$ at the primary hospital before transfer [16]

Prompt patient management is a mainstay of trauma care [17]; thus, any unnecessary repeat tests may delay appropriate treatment. Trauma surgeons have long recognized the so-called golden hour, the critical period of time to begin definitive treatment of patients who have suffered serious trauma [18]. The American College of Surgeons Committee on Trauma has recognized that within this golden hour, the aim of resuscitation for these patients is to achieve respiratory and hemodynamic stabilization [17]. It has been shown that treatment delays from prehospital care to in-hospital procedures, such as prolonged radiographic examinations times, can have a deleterious effect on the patient [19].

Thus, reducing duplicate CTs could minimize patient delay. One way to do this would be to enable tertiary hospitals access to the primary hospitals PACS. Liepert et al., 2014, found a $33 \%$ reduction in duplicate CT scans when tertiary hospitals had access to primary receiving hospital CT scans [20]. Implementation of statewide radiological image repositories has been shown to reduce the following: repeat CT scans, significant costs, radiation exposure, and LOS in the ED for patients with less complex injuries [21]. The Arkansas trauma image repository (TIR) is a portal through which $\mathrm{CT}$ images can be sent from the primary receiving hospital making the CT information available for upload into the tertiary transferring hospital's PACS (Fig. 1). The purpose of this study was to compare two different states image handling systems, one with a TIR and one without, for trauma patient transfers to a single hospital utilizing rate of duplicate CT scans as a patient benefit metric.

\section{Methods}

\section{Setting}

The primary hospital is the originating hospital where the patient initially received treatment. The tertiary hospital is the referral hospital where the patient was transported for more specialized care. In this study, the tertiary hospital is a single level 1 trauma center which receives trauma patients via transfer from hospitals in either Arkansas or Missouri (Fig. 1) after initial stabilization. These hospitals utilize a digital PACS to record and view radiological images. Implementation of the Arkansas image repository began July 2013 [22] within the tertiary hospital. In order to evaluate the change in duplication rates over time, data was analyzed a year before and after the image repository implementation.

\section{Sample}

Between July 2012 and June 2015, 2460 patients were transferred from outlying hospitals in Arkansas and Missouri into a single tertiary hospital (for a demographics overview, see Table 1). The total number of trauma transfer patients including a $\mathrm{CT}=1476$, with the total number of duplicate CT scans, is 194 (13.1\%). Patients
Fig. 1 Flow from patient trauma through to the tertiary hospital

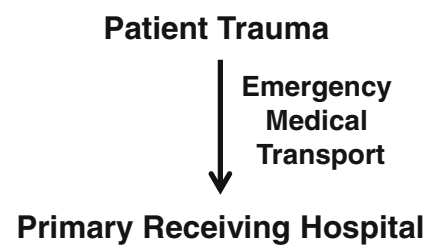

Arkansas

Trauma Communication System

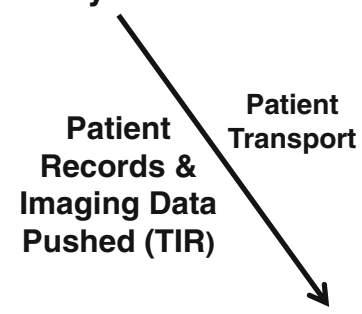

Tertiary Receiving

Hospital 
Table 1 Data averaged across the 3 years

\begin{tabular}{|c|c|c|c|}
\hline & & Arkansas & Missouri \\
\hline \multirow[t]{6}{*}{ Demographics } & $\begin{array}{l}\text { Patient transfers including at least } \\
\text { one CT }(n)\end{array}$ & 853 & 623 \\
\hline & Age (year), Avg. ( $\pm \mathrm{SD})$ & $45.3( \pm 25.7)$ & $51.7( \pm 25.5)$ \\
\hline & Female (sex), $n(\%)$ & $288(33.8 \%)$ & $236(37.8 \%)$ \\
\hline & Total primary receiving hospitals $(n)$ & 28 & 36 \\
\hline & $\begin{array}{l}\text { Most frequent trauma level (1-3) } \\
\text { primary hospital, level (overall \%) }\end{array}$ & $3(87.8 \%)$ & $3(77.3 \%)$ \\
\hline & Avg. injury severity score $( \pm \mathrm{SD})$ & $10.2( \pm 8.6)$ & $10.3( \pm 7.0)$ \\
\hline \multirow[t]{13}{*}{ Injury etiology } & Motor vehicle (including motorcycles), $n(\%)$ & $272(31.9 \%)$ & $225(36.1 \%)$ \\
\hline & Pedestrian, $n(\%)$ & $21(2.5 \%)$ & $8(1.3 \%)$ \\
\hline & Fall, $n(\%)$ & $289(33.9 \%)$ & $261(41.9 \%)$ \\
\hline & Gunshot, $n(\%)$ & $27(3.2 \%)$ & $13(2.1 \%)$ \\
\hline & Stabbing, $n(\%)$ & $13(1.5 \%)$ & $14(2.2 \%)$ \\
\hline & Other, $n(\%)$ & $231(27.1 \%)$ & $102(16.4 \%)$ \\
\hline & Total CT scans $(n)$ & 2360 & 1207 \\
\hline & Avg. CT scans per person & 2.8 & 1.9 \\
\hline & ICD-9 codes, $n(\%)$ & & \\
\hline & 87.03 & $678(28.7 \%)$ & $381(31.6 \%)$ \\
\hline & 87.41 & $367(15.6 \%)$ & $220(18.2 \%)$ \\
\hline & 88.01 & $409(17.3 \%)$ & $247(20.5 \%)$ \\
\hline & 88.38 & $906(38.4 \%)$ & $359(29.7 \%)$ \\
\hline
\end{tabular}

who did not receive a CT scan from the primary hospital or $<18$ years old were excluded from the study.

\section{Data analysis}

This retrospective analysis examined CT duplication rates using a method previously described by Mohan et al. (2010) [11]; study data was extracted from the tertiary hospital's trauma registry. The number of patients with a duplicate $\mathrm{CT}$ within $24 \mathrm{~h}$ of arrival was identified by matching exact exam types utilizing ICD-9 codes (CT head, 87.03; CT thorax, 87.41; CT abdomen, 88.01; CT other, skeletal 88.38). Duplication of a CT was defined as a patient who had at least one CT scan at an outlying primary hospital and then transferred to the tertiary hospital receiving the exact same CT scan while in the emergency department or within $24 \mathrm{~h}$ of arrival.

Duplication rates were calculated for patients meeting the duplicate $\mathrm{CT}$ definition and inclusion criteria. These rates were calculated as one per patient not per $\mathrm{CT}$, despite the number of duplicate CTs a multiple injury patient may have received. For example, a trauma patient with three duplicate CTs (head, thorax, and abdomen) was only counted as one duplicate CT.

The data was divided into three phases to demonstrate impact of TIR implementation and measure its sustainability over a 2-year period: pre-TIR implementation year (July 2012-June 2013), implementation year (July 2013-
June 2014), and follow-up year (July 2014-June 2015) to show any continued maintainable effect.

\section{Statistics}

Due to the seasonal differences in trauma patient transfer volume, duplicate CT percentage was calculated [11] per quarter, expressed as average percentile across 12 months \pm standard deviation. A two-tailed Student's $t$ test was used to compare CT duplication rates for each study year for trauma patients transferred from Arkansas and Missouri, respectively, in a year; results were accepted as significant when the CI 95\%, $p \leq 0.05$.

The study received approval from the Mercy Institutional Ethics Review Board. For this type of study, formal consent is not required.

\section{Results}

Averaged across the whole timeframe of this study (shown in Table 1), Arkansas and Missouri patients have similar demographics; however, trauma patients transferred from Arkansas received an average of 2.8 CT scans per person, as compared to those transferred from Missouri who received an average of 1.9 CT scans per person.

Exploring the data within the yearly phases of this study, the CT duplication rate decreased each year after TIR 
introduction for patients transferred from Arkansas; in year 1, the duplication rate was $11.5 \% \pm 2.8$, and the two subsequent years showed reductions, $10.1 \% \pm 3.4$ (year 2) and 9.0\% \pm 2.2 (year 3). For those patients transferred from Missouri, there was little change from year $1(16.3 \% \pm 7.5)$ to year $2(16.2 \%$ \pm 2.4 ), followed in year 3 by a slight increase to $17.8 \% \pm 3.4$.

Prior to implementation of the Arkansas TIR, there was no significant difference in duplication rate between Missouri and Arkansas transfer patients. From year 2, comparing the duplicate $\mathrm{CT}$ rate between the states, Arkansas transfers were significantly lower than those in Missouri for each of the subsequent years after the TIR was implemented ( $p \leq 0.02$; Fig. 2).

\section{Discussion}

From a purely hypothetical perspective, the implementation of a TIR and trauma communication system (see Fig. 1), by reducing unnecessary repeat $\mathrm{CT}$ s should have a positive effect on transfer time, patient care costs, and radiation exposure. This is corroborated in the literature, where PACS implementation between hospitals shows reduction in the duplicate CT rates in trauma transfers $[13,23]$. Furthermore, the literature shows reducing duplicate $\mathrm{CT}$ rates that reduces patient exposure and care costs [3]. Thus, the goal for this study was to determine whether implementation of a state-level PACS-like system within a trauma paradigm would impact duplicate CT scan rates.

First, when compared between the two states, Arkansas patients transferring from primary hospitals received more CT scans per person than those transferring from Missouri primary hospitals. However, Arkansas patients received fewer CT duplications than those patients from Missouri. Secondly, when examined by year, fewer Arkansas patients received duplicate CT scans after the integration into our hospital PACS (June 2013). Furthermore, comparing the Arkansas and Missouri transfer patients, we show the implementation
Fig. 2 Comparing the originating state transfers in relation to duplicate CT scans into a level 1 trauma facility. Data was separated according to the originating hospital state (Arkansas; Missouri) then quarterly data averaged across a year (years 1, 2, and 3). Duplicate $\mathrm{CT}$ percentage was calculated by taking the number of patients with duplicate CTs in a quarter and dividing by the total number of trauma patient transfers that include a CT scan in that quarter. a Error bars are standard deviation; the asterisk symbol indicates a two-tailed $p$ value $\leq$ 0.02 . Black arrow denotes date Arkansas trauma repository upgrade was integrated into the SW Missouri trauma level I center PACS. b $p$ values $\leq 0.05$ were considered significant

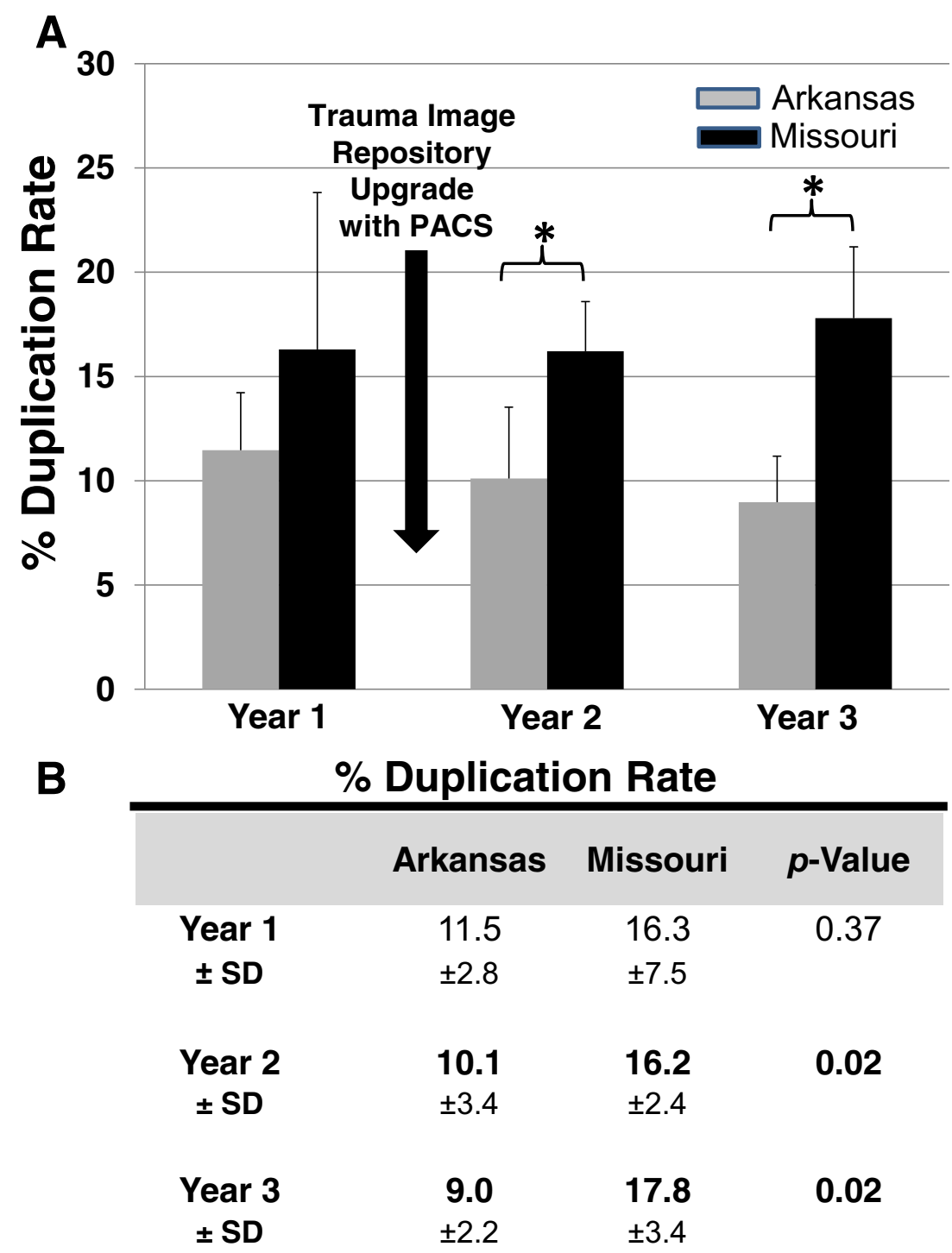


of the TIR, again, introduces a point that separates the patient CT duplication data (Fig. 2) that is further solidified during year 3.

Although not examined, one plausible factor between the various hospital systems each has to follow is the state regulations for trauma. The Missouri state trauma system inception was in the 1990s [24], but the Arkansas state trauma system began in 2009 [25]. The advantage for the later Arkansas inception date allowed inclusion of web sharing-based applications (TIR) into the state regulations, thus requiring greater interoperability between the various hospitals chosen imaging file types for compatibility with the TIR.

\section{Conclusion}

In conclusion, these findings suggest that the adoption by the tertiary hospital of a state-level TIR eventually led to a $22 \%$ reduction in CT duplication when comparing Arkansas transfer patients. When comparing between the Arkansas and Missouri transfer patients, there is a $50 \%$ reduction in $\mathrm{CT}$ duplication.

\section{Limitations}

This study includes data compiled from only a single center, lacking comparison to other hospitals and inability to warrant whether repeat $\mathrm{CT}$ was performed for clinically validated reasons.

There are several issues that may impede data transfers between primary and receiving hospitals: radiologist delay in reading CT scan and uploading report and technical problems due to incompatibility, damaged, lost, or unreadable CDs [26].

Compliance with ethical standards The study received approval from the Mercy Institutional Ethics Review Board. For this type of study, formal consent is not required.

Conflict of interest The authors declare that they have no conflict of interest.

Open Access This article is distributed under the terms of the Creative Commons Attribution 4.0 International License (http:// creativecommons.org/licenses/by/4.0/), which permits unrestricted use, distribution, and reproduction in any medium, provided you give appropriate credit to the original author(s) and the source, provide a link to the Creative Commons license, and indicate if changes were made.

\section{References}

1. (US) IoM (2010) Regionalized trauma care: past, present, and future. In: Regionalizing emergency care: workshop summary. National Academies Press (US), Washington (DC)
2. Liberman M, Mulder DS, Jurkovich GJ, Sampalis JS (2005) The association between trauma system and trauma center components and outcome in a mature regionalized trauma system. Surgery 137(6):647-658. https://doi.org/10.1016/j.surg.2005.03.011

3. Hinzpeter R, Sprengel K, Wanner GA, Mildenberger P, Alkadhi H (2017) Repeated CT scans in trauma transfers: an analysis of indications, radiation dose exposure, and costs. Eur J Radiol 88:135140. https://doi.org/10.1016/j.ejrad.2017.01.007

4. Gupta R, Greer SE, Martin ED (2010) Inefficiencies in a rural trauma system: the burden of repeat imaging in interfacility transfers. J Trauma 69(2):253-255. https://doi.org/10.1097/TA. 0b013e3181e4d579

5. Kulshrestha A, Singh J (2016) Inter-hospital and intra-hospital patient transfer: recent concepts. Indian J Anaesth 60(7):451-457. https://doi.org/10.4103/0019-5049.186012

6. Vali Y, Rashidian A, Jalili M, Omidvari AH, Jeddian A (2017) Effectiveness of regionalization of trauma care services: a systematic review. Public Health 146:92-107. https://doi.org/10.1016/j. puhe.2016.12.006

7. Choplin RH, Boehme JM II, Maynard CD (1992) Picture archiving and communication systems: an overview. Radiographics 12(1): 127-129. https://doi.org/10.1148/radiographics.12.1.1734458

8. Becker SH, Arenson RL (1994) Costs and benefits of picture archiving and communication systems. J Am Med Inform Assoc 1(5):361-371. https://doi.org/10.1136/jamia.1994.95153424

9. Crowe BL (1992) Overview of some methodological problems in assessment of PACS. Int J Biomed Comput 30(3-4):181-186. https://doi.org/10.1016/0020-7101(92)90019-O

10. Korley FK, Pham JC, Kirsch TD (2010) Use of advanced radiology during visits to US emergency departments for injury-related conditions, 1998-2007. JAMA 304(13):1465-1471. https://doi.org/10. 1001/jama.2010.1408

11. Mohan D, Barnato AE, Angus DC, Rosengart MR (2010) Determinants of compliance with transfer guidelines for trauma patients: a retrospective analysis of CT scans acquired prior to transfer to a level I trauma center. Ann Surg 251(5):946-951. https://doi.org/10.1097/SLA.0b013e3181d76cb5

12. Haley T, Ghaemmaghami V, Loftus T, Gerkin RD, Sterrett R, Ferrara JJ (2009) Trauma: the impact of repeat imaging. Am J Surg 198(6): 858-862. https://doi.org/10.1016/j.amjsurg.2009.05.030

13. Moore HB, Loomis SB, Destigter KK, Mann-Gow T, Dorf L, Streeter MH, Ebert GM, Crookes BA, Leffler SM, O'Keefe MF, Freeman K (2013) Airway, breathing, computed tomographic scanning: duplicate computed tomographic imaging after transfer to trauma center. J Trauma Acute Care Surg 74(3):813-817. https:// doi.org/10.1097/TA.0b013e3182789399

14. Chwals WJ, Robinson AV, Sivit CJ, Alaedeen D, Fitzenrider E, Cizmar L (2008) Computed tomography before transfer to a level I pediatric trauma center risks duplication with associated increased radiation exposure. J Pediatr Surg 43(12):2268-2272. https://doi. org/10.1016/j.jpedsurg.2008.08.061

15. Daffner RH (2000) Cervical radiography for trauma patients: a time-effective technique? AJR Am J Roentgenol 175(5):13091311. https://doi.org/10.2214/ajr.175.5.1751309

16. Onzuka J, Worster A, McCreadie B (2008) Is computerized tomography of trauma patients associated with a transfer delay to a regional trauma centre? CJEM 10(3):205-208. https://doi.org/10. $1017 / \mathrm{S} 1481803500010113$

17. (2013) Advanced trauma life support (ATLS(R)): the ninth edition. J Trauma Acute Care Surg 74(5):1363-1366. https://doi.org/10. 1097/TA.0b013e31828b82f5

18. Trunkey DD (1983) Trauma. Accidental and intentional injuries account for more years of life lost in the U.S. than cancer and heart disease. Among the prescribed remedies are improved preventive efforts, speedier surgery and further research. Sci Am 249(2):2835. https://doi.org/10.1038/scientificamerican0883-28 
19. McNicholl BP (1994) The golden hour and prehospital trauma care. Injury 25(4):251-254. https://doi.org/10.1016/0020-1383(94)90073-6

20. Liepert AE, Bledsoe J, Stevens MH, Cochran A (2014) Protecting trauma patients from duplicated computed tomography scans: the relevance of integrated care systems. Am J Surg 208(4):511-516. https://doi.org/10.1016/j.amjsurg.2014.05.014

21. Watson JJJ, Moren A, Diggs B, Houser B, Eastes L, Brand D, Bilyeu P, Schreiber M, Kiraly L (2016) A statewide teleradiology system reduces radiation exposure and charges in transferred trauma patients. Am J Surg 211(5):908-912. https://doi.org/10.1016/j. amjsurg.2016.01.010

22. Imus T (2016) Personal Communication to C. L. Austin: Implementation of an Arkansas TIR upgrade enabled integration into the Mercy Springfield PACS environment
23. Sung JC, Sodickson A, Ledbetter S (2009) Outside CT imaging among emergency department transfer patients. J Am Coll Radiol 6(9):626-632. https://doi.org/10.1016/j.jacr.2009.04.010

24. Carnahan R (2012) Department of Health and Senior Services. Division 30- division of regulation and licensure. Chapter 40 comprehensive emergency medical services systems regulations. Missouri Department of Health and Senior Services, https://www. sos.mo.gov/CMSImages/AdRules/csr/current/19csr/19c30-40.pdf

25. Health ASBo (2014) In: Arkansas State Board of Health (ed) Arkansas Trauma System Regulations https://www.healthy. arkansas.gov/images/uploads/rules/TraumaSystems.pdf

26. Vreeland A, Persons KR, Primo HR, Bishop M, Garriott KM, Doyle MK, Silver E, Brown DM, Bashall C (2016) Considerations for exchanging and sharing medical images for improved collaboration and patient care: HIMSS-SIIM collaborative white paper. J Digit Imaging 29(5):547-558. https://doi.org/10.1007/s10278-016-9885-X 